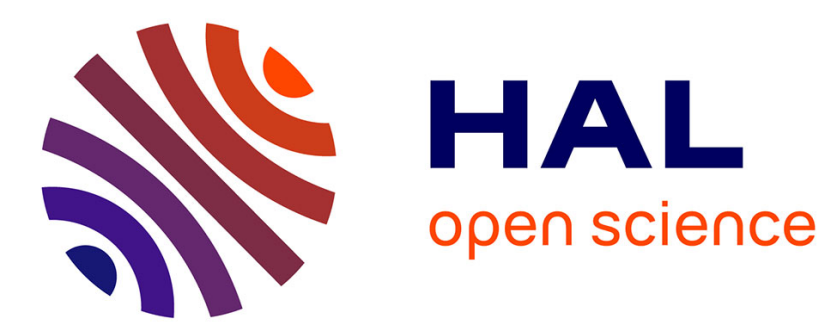

\title{
PULSED LASER DEPASSIVATION OF METALLIC ELECTRODES IN AQUEOUS CORROSIVE MEDIA
}

\author{
R. Oltra, G. Indrianjafy, J. Boquillon
}

\section{To cite this version:}

R. Oltra, G. Indrianjafy, J. Boquillon. PULSED LASER DEPASSIVATION OF METALLIC ELECTRODES IN AQUEOUS CORROSIVE MEDIA. Journal de Physique IV Proceedings, 1991, 01 (C7), pp.C7-769-C7-774. 10.1051/jp4:19917206 . jpa-00250887

\section{HAL Id: jpa-00250887 https://hal.science/jpa-00250887}

Submitted on 1 Jan 1991

HAL is a multi-disciplinary open access archive for the deposit and dissemination of scientific research documents, whether they are published or not. The documents may come from teaching and research institutions in France or abroad, or from public or private research centers.
L'archive ouverte pluridisciplinaire HAL, est destinée au dépôt et à la diffusion de documents scientifiques de niveau recherche, publiés ou non, émanant des établissements d'enseignement et de recherche français ou étrangers, des laboratoires publics ou privés. 


\title{
PULSED LASER DEPASSIVATION OF METALLIC ELECTRODES IN AQUEOUS CORROSIVE MEDIA
}

\author{
R. OLTRA, G.M. INDRIANJAFY and J.P. BOQUILLON* \\ URA CNRS 23 Réactivité des Solides, BP. 138, F-21004 Dijon, France \\ ${ }^{*}$ URA CNRS 777 Spectronomie Moléculaire et Instrumentation Laser, BP. 138, F-21004 Dijon, France
}

\begin{abstract}
A large amount of metallic materials in aqueous media (e.g. stainless steels, Nickel alloys....) are protected from localized aqueous corrosion by thin oxide films grown in situ which passivate the metallic surfaces. The passivity can be disturbed by ionic breakdown or imposed mechanical breakdown of the protective film. In the conventional corrosion studies, a lot of techniques have been developed to simulate a local damage of the passive film which don't allow to reach the electrochemistry of bare metal surface. In this work, a pulsed Nd-YAG Laser and a pulse dye Laser in the range of 1 to $10 \mathrm{MW} / \mathrm{cm}^{2}$ have been tested to promote a local ablation of the passive film in corrosive media. This paper will be mainly devoted to the analysis of the interaction of the laser beam with a thin passive film in presence of an electrolyte.
\end{abstract}

\section{INTRODUCTION}

\section{Background on localized corrosion}

A large amount of metallic materials in aqueous media (e.g. stainless steels, Nickel alloys....) are protected from localized aqueous corrosion by thin oxide films grown in situ.

Passivation of metals results from the formation of thin surface oxide layers, which are described as cristalline oxide films or gel-like hydroxide films of which the thickness varies from 1 to 10 nanometers (1). Charge transfer occurs at the electrochemical double layer and outer part of the film which contains anions of the electrolyte. While the inner part of the film consists of a dehydrated oxide. The presence of this film reduces the anodic ion-transport leading to the corrosion resistance of the metal which is "passivated". The passivity can be disturbed by ionic breakdown or imposed mechanical breakdown of the protective film.

lonic breakdown is due to a competition between adsorption of hydroxyl ions and agressive ions. Different mechanisms like local chloride salt film formation, induction of local mechanical stresses have been proposed to describe local film breakdown which accelerates the local metal dissolution inducing pitting corrosion.

On the other hand pure mechanical breakdown of the passive film can be achieved by:

"straining the metallic substrat: the stresses applied to the metal-film interface lead to local breakdown of the film on the slip bands and can induce cracking.

*abrading the metallic surface (mechanical removal of the passive film). 
The final stage of mechanical breakdown, in terms of corrosion, is under the control of a dynamic balance between the local dissolution of the bare metal and the rebuilt of the passive layer. As function of this dynamic balance the mechanical breakdown leads to either localized corrosion or repassivation. This phenomena has been studied by coupling various techniques to the analysis of the transient electrochemical response (2).

In many studies the part up to the current peak is assumed to correspond to the dissolution and the part following the current peak is considered to be related to the repassivation process. Nevertheless some contreversy has been claimed recently regarding the electrochemical analysis of such current transient (3). The main question is to estimate which parts in the current transient are respectively devoted to the recharge of the double layer and to the dissolution and repassivation of the bare metal.

\section{Laser technique}

A correct analysis of the current response of a bare metal surface needs the generation of the new surface to be in a reduced time and controlled in size. In previous studies the spatial facilities of the Laser beam have been used to investigate the electrical coupling between the depassivated and the unaffected surrounding passive surface in case of localized corrosion, whereas the short-time (in the range of the microsecond) of the Laser interaction allows to introduce the concept of the transfer function of the electrochemical cell during a depassivation-repassivation sequence $(4,5)$.

Nevertheless in these studies the physical nature of the Laser interaction was not clearly investigated.

From an experimental point of view a dye pulsed Laser $(600 \mathrm{~nm})$ pumped by flashlamps has been first used in the range of $1 \mathrm{MW} / \mathrm{cm}^{2}$ with a pulse length of $1 \mu \mathrm{s}$. The experimental results have been described in previous publications $(4,5)$. More recently a pulsed Nd-YAG Laser $(1064 \mathrm{~nm})$ in the range of 1 to $10 \mathrm{MW} / \mathrm{cm}^{2}$ has been tested.

It can be noticed that in situ Laser radiation at the same level of power density has been used to activate solid electrodes, i.e. to remove passivating polymeric films caused by phenol oxydation on a glassy carbon electrode (6). In presence of a corroding media Laser pulses of higher power density $\left(10 \mathrm{GW} / \mathrm{cm}^{2}\right)$ allowed to initiate pitting corrosion on metallic targets (7). At relatively lower density of energy the radiation of a Nd-YAG laser has been used to perform photoelectrochemistry (Laser-induced transient open circuit photovoltages) on semi-conductor electrodes (8).

\section{Laser - passive film interaction.}

Some comparison can be attempted with the mechanism involved in the Laser enhanced chemical or electrochemical etching (9). Elevation of temperature due to the absorption of the Laser energy has been claimed as the main interaction involved in the enhancement of the localized chemical or electrochemical reaction. On the other hand nonthermal effects such as atomic desorption enhanced by a shock wave has been assumed by other authors allowing the use of Laser beams as a cleaning technique for surface analysis (10). Since a large domain of pulse duration is involved in all the different systems the fluence $\left(\mathrm{J} / \mathrm{cm}^{2}\right)$ seems to be the more convenient parameter to characterize the nature of interaction. As shown in the diagram (Fig. 1) the selected working domain $\left(1 \mathrm{~J} / \mathrm{cm}^{2}\right)$ falls at the boundary of the well-known areas of the Laser 
applications in metallurgy allowing to reject the most tremendous perturbations of the metallic surface.

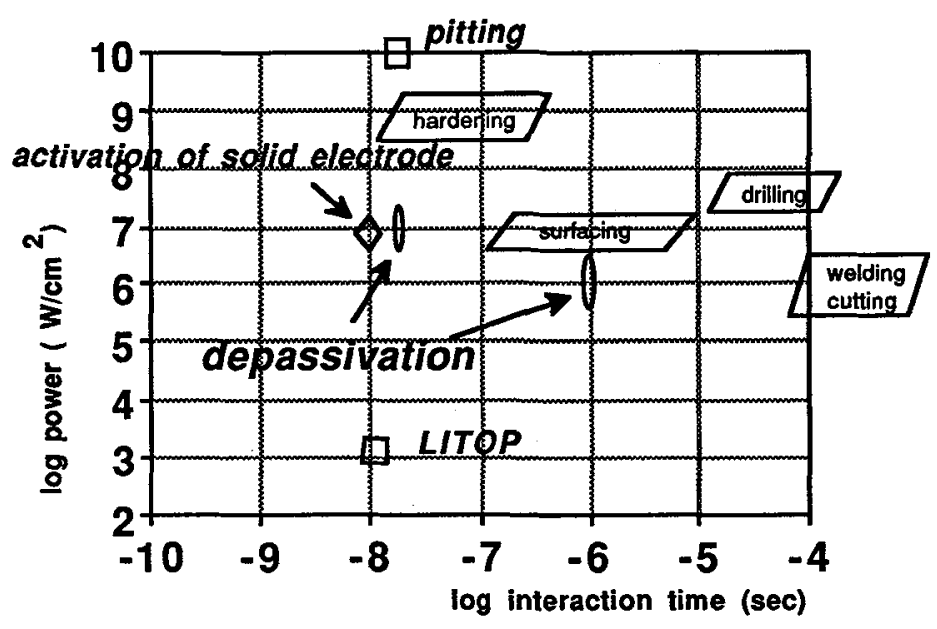

Fig. 1-Interaction of Laser with electrodes compared to the conventional applications of Laser in metallurgy

\section{EXPERIMENTAL}

\section{Materials}

The depassivation experiments in acidic solution $\left(\mathrm{HClO}_{4}, \mathrm{pH}=1\right.$, room temperature) have been carried on pure iron electrodes designed from wire electrodes of $0.250 \mathrm{~mm}$ in diameter.

The electrochemical responses have been recorded either in free corrosion conditions or under potentiostatic control.

\section{Depassivating effect of Laser Illumination.}

A typical experiment has been carried out with a passive electrode in free corroding conditions. The potential decay after polarisation in the passive range is clearly modified after Laser illumination of the passive surface. This latter shifts the potential towards the open circuit potential, i.e. $-900 \mathrm{mV}$ vs SSE, demonstrating the depassivation of the surface (Fig.2a). If the mechanism involved in the Laser beam interaction with the surface remains to clarify, undoubtly it promotes a depassivation.

\section{Current transients on passive Iron in acidic solution}

A typical current transient is shown in Fig.2b. Comparing to the Laser pulse (illumination peak recorded on a photodiode) the electrochemical response is delayed. A more detailed analysis of the current response in terms of corrosion has been proposed previously $(4,5)$. In this paper the electrochemical system will be considered mainly as a probe in order to describe the nature of the interaction.

The electrical charge involved in the transient response is the sum of the charge of the double layer and the faradaic reactions corresponding to the anodic dissolution and to the rebuilt of the passive film itself. 

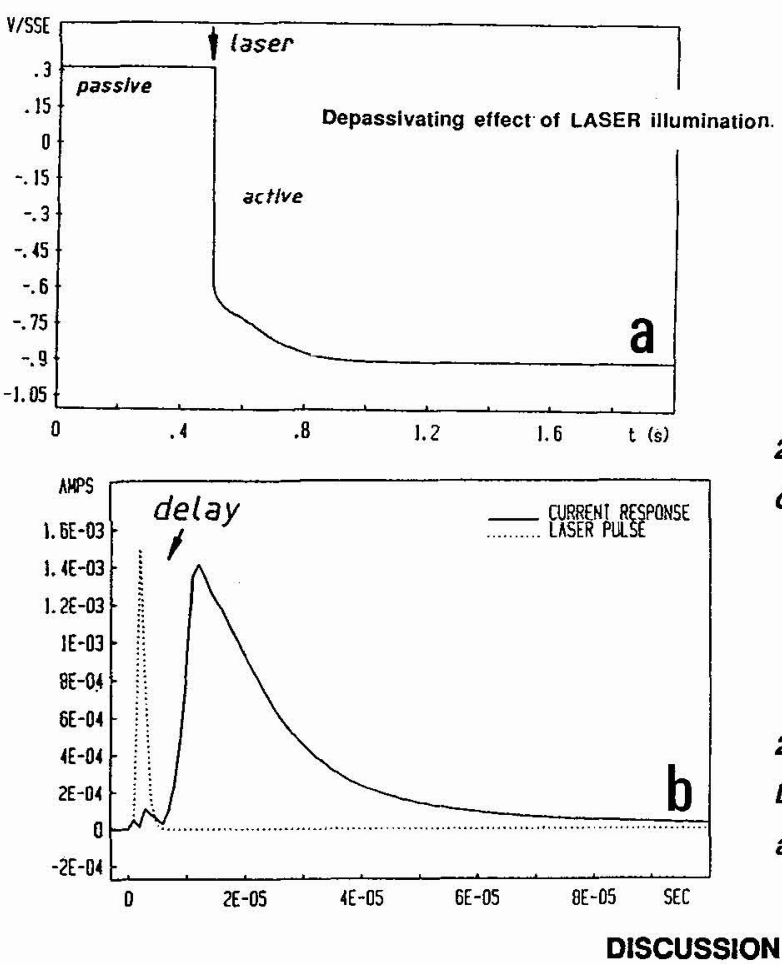

Fig.2- electrochemical responses for a passive electrode

2a: change in the free corrosion potential decay after Laser pulse

$2 b$ : current transient (Amps.) and Laser pulse (abitrary units) at imposed potential - Eimp. $=+300 \mathrm{mV} / \mathrm{SSE}$

This discussion will concern the mechanisms to explain passive film breakdown. It can be noticed that the range of the $10^{7} \mathrm{~W} / \mathrm{cm}^{2}$ has been described in the literature as a threshold value for ablation of metallic material (12). With an incident Laser pulse below this value the increase in temperature due to the Laser pulse is sufficiently small to avoid any change of state in the case of a solid material, and elastic stresses are obtained at the surface by bulk thermal expansion: this phenomena is defined as the thermoelastic effect. In this situation the forces act in direction parallel to the surface (13).

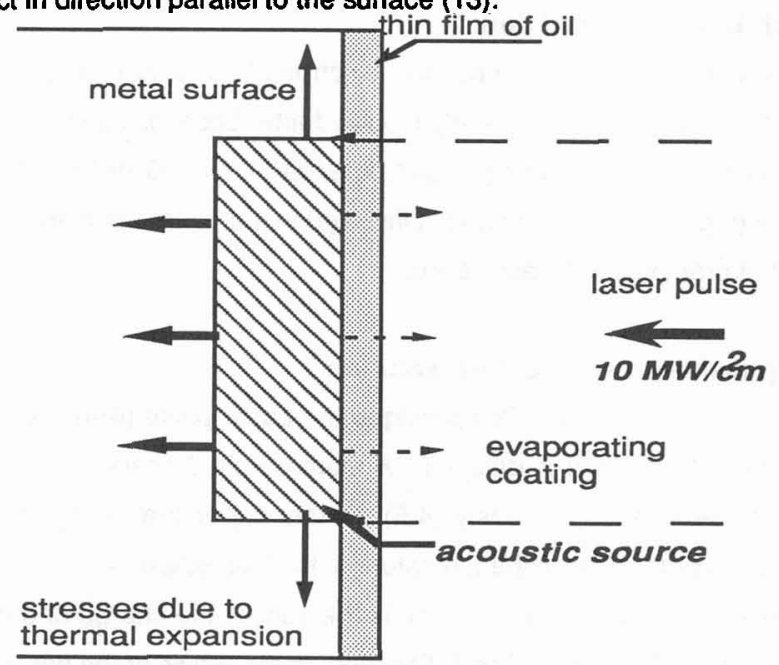

Fig.3- schematic representation of the thermoelastic effect in presence of a thin film of oil, liquid.. (from 13) 
The damaged region, i.e. the acoustic source, is located just under the surface. More interesting results have been described when the irradiated metalic surface was coated by thin film of liquid,i.e. oil acetone, water... (13). The Laser energy tends to be absorbed in the liquid phase promoting liquid evaporation and large increase in compressive stresses at the surface of the material as shown in Fig.3.

Recent experiments allows us to follow the change of the mass of the target described in Fig. 3 during the Laser pulse on metallic foils covered with a thin film of oil: in fact the term of evaporation (thermal effect) is not valid as the deposited mass of oil has been collected on a glass plate positionned in front of the foil: it can be concluded that the thin film of oil is ejected by a mechanical effect and is not vaporized. This analysis can be transfered to the case of the metal-electrolyte interface behavior under pulse Laser irradiation. As function of the specific nature of this interface (a sandwich consisting on the metal substrate, the film and the bulk electrolyte), the acoustic source will be assumed located at the internal interface of the "sandwich," i.e. the film-metal interface will be strained. Assuming no absorption of the passive film, by reaction to the compressive stress at the inner interface two effects will occur at the outer interface as shown in Fig.7:

-the ejection on the passive film by mechanical reaction of the substrate.

-cavitation in the electrolyte leading to the destruction of the double layer

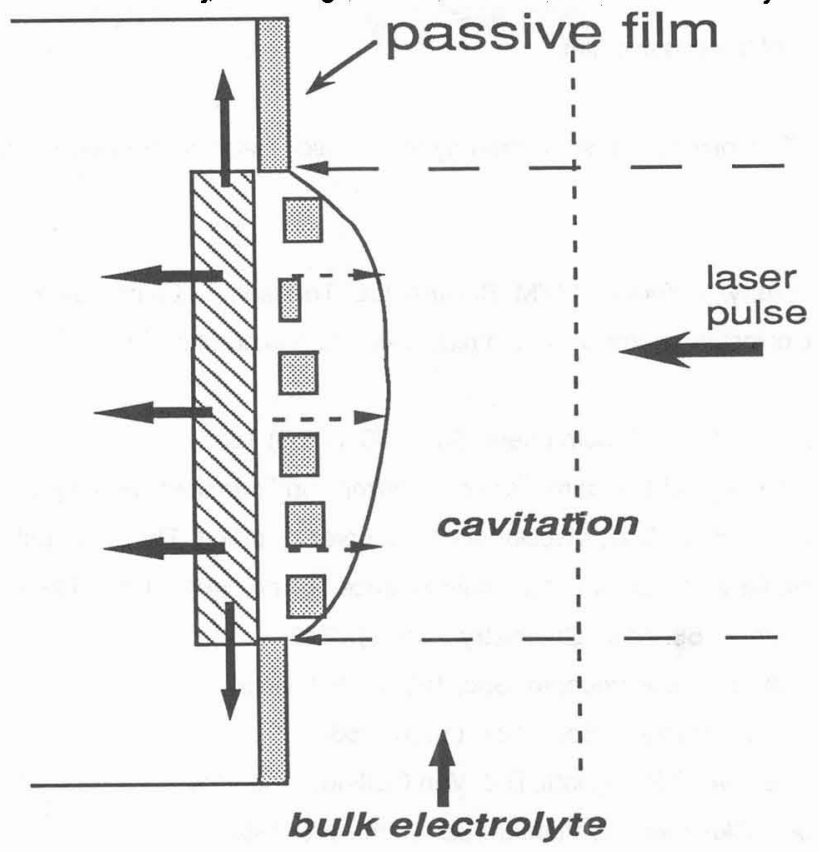

Fig.4- schematic diagram of the physical phenomena induced by puised Laser irradiation of a metallic electrode covered with a thin oxide film in contact with a bulk electrolyte (model transfered from ref. 1.3)

From an experimental point of view the first effect due to cavitation has been checked by the delay in the electrochemical response as mentionned previously (Fig.4). It is clear that the current transient will contain always the contribution of the recharge of the double layer. 
assumed as the main physical effect which can promote the passive film breakdown. In the range of $107 \mathrm{~W} / \mathrm{cm}^{2}$ the Laser perturbation of a passive surface induces cavitation and the ejection of the passive film. Cavitation leads to the transient recharge of the double layer. Whereas a repassivation transient related to faradaic reaction can be observed as function of a the level of the thermoelastic effect assuming no laser absorption by the passive film. Secondary effects like photoelectrochemical interaction can be assumed to play a minor role in the response in the range of $10 \mathrm{MW} / \mathrm{cm}^{2}$ (8).

\section{CONCLUSION}

By analogy with the generation of compressive stresses at the surface of metallic surfaces coated with film of water or oil, due to a thermoelastic effect, the pulsed Laser irradation of a metallic electrode protected of the corrosion by a passive film has been analysed in terms of two contributions: a thermomechanical effect at the inner part of the metal-electrolyte interface resulting on a mechanical ejection of the passive film and cavitation in the electrolyte. The electrochemical responses after the Laser pulse, i.e. the corrosion current or the corrosion potential transients, allow to check these two contributions. As regards the corrosion properties of the passive films the Laser interaction can be regarded as a mechanical probe in order to investigate the critical stress for breakdown of the passive film.

Acknowledgments: This program is supported by the Conseil Régional de Bourgogne

\section{References}

(1) T.E. Pou, O.J. Murphy, V.Young, J.O'M. Bockris, L.L. Tongson, J.Electrochem. Soc., 131, (1984), 1243

(2) R.C. Newman, Corrosion chemistry within pits, crevices and cracks, Ed. A. Turnbull, p. , HMSO, LONDON, 1987

(3) R.P. Wei, M.Gao, P.Y. Xu, J. Electrochem. Soc, 136, (1989) 1835

(4) R.Oltra, G.M.Indrianjafy, M.Keddam, Proceed. Symp. on "transient techniques in corrosion science and engineering", Eds. W.H. Smyrl, D.D; MacDonald, W.J. Lorenz, p.363, The Electrochemical Society, 1989

(5) R.Oltra, G.M.Indrianjafy, M.Keddam, Materials Science Forum, 44/45, (1989) 259

(6) M.Poon,, R.L.McCeery, 58, Anal. Chemistry , (1986) 2745

(7) R.K. Ulrich, R.C. Alkire, J.Electrochem. Soc, 128, (1981) 1169

(8) Perone and coll., J.Electrochem.Soc., 127, (1980) 2580

(9) M.Datta, L.T. Romankiw, D.R. Vigliotti, R.J. Von Gutfeld, Appl.Phys.Lett., 51, (1987) 2040

(10) P.L. Cowan , J.A. Golovchenko., Vacuum Sc. Tech., 17, (1980) 5

(11) M.Baddi, G.Gabrielli, M.Keddam, H.Takenouti, Passivity of Metals, Eds.R.P. Frankenthal and J.Kruger, p.625, 1978

(12) J.D.Aussel, A.Le Brun, J.C. Baboux, Ultrasonics,26, (1988) 245

(13) D.A. Hutchins, D.E. Wilkins, J.Appl.Phys., 58, (1985) 2489

(14)B.P. Fairand, A.H. Clauer, J.Appl. Phys. 50, (1979)1497 